\title{
Outcome of severe traumatic brain injury: comparison of three monitoring approaches
}

\author{
Ruwaida Isa, M.B., Ch.B., M.Med. (Anaest), \\ Wan Aasim Wan Adnan, M.B., Ch.B., M.Med. (Anaest), \\ Ghazaime Ghazali M.D., F.R.C.A. (IREL), Zamzuri Idris, M.B., Ch.B., \\ Abdul Rahman Izaini Ghani, M.B., B.S., Sani SaYUTHI, M.B., B.S., \\ Mohamed Saufi Awang, M.B., B.S., Mazira Mohamad Ghazali, B.Sc., \\ Nyi Nyi Naing, M.B., B.S., M.Med. (Stats), and Jafri Malin Abdullah, M.D., Ph.D. \\ Department of Anesthesiology and Critical Care Medicine; and Neurosciences and Biostatistic and \\ Research Methodology Units, School of Medical Sciences, Universiti Sains Malaysia, Kelantan, \\ Malaysia
}

\begin{abstract}
The determination of cerebral perfusion pressure (CPP) is regarded as vital in monitoring patients with severe traumatic brain injury. Besides indicating the status of cerebral blood flow (CBF), it also reveals the status of intracranial pressure (ICP). The abnormal or suboptimal level of CPP is commonly correlated with high values of ICP and therefore with poor patient outcomes. Eighty-two patients were divided into three groups of patients receiving treatment based on CPP and CBF, ICP alone, and conservative methods during two different observation periods. The characteristics of these three groups were compared based on age, sex, time between injury and hospital arrival, Glasgow Coma Scale score, pupillary reaction to light, surgical intervention, and computerized tomography scanning findings according to the Marshall classification system. Only time between injury and arrival $(\mathrm{p}=0.001)$ was statistically significant. There was a statistically significant difference in the proportions of good outcomes between the multimodality group compared with the group of patients that underwent a single intracranial-based monitoring method and the group that received no monitoring $(\mathrm{p}=0.003)$ based on a disability rating scale after a follow up of 12 months. Death was the focus of outcome in this study in which the multimodality approach to monitoring had superior results.
\end{abstract}

\section{KEY WORDS • cerebral perfusion pressure • traumatic brain injury • intracranial pressure monitoring $\bullet$ cerebral blood flow}

Ischemic brain damage is extremely common after severe head injury. Eighty to $90 \%$ of patients who die of TBI show ischemia on histopathological examination of the brain. ${ }^{2}$ The cerebral metabolic rate probably increases transiently and therefore substrate demand may vary over time, being the highest early after trauma, which makes an increase in substrate delivery via CBF necessary. ${ }^{1,17,18,24}$ Nonetheless, in approximately one third of patients, CBF is low in the early phase after TBI. ${ }^{6}$ Early flow-metabolism mismatch may cause secondary damage to neurons. The optimal method for measuring CBF has yet to be discovered. Due to the anatomical difficulties inherent in accessing the central nervous system, quantitative mea-

Abbreviations used in this paper: $\mathrm{BBB}=$ blood-brain barrier; $\mathrm{CBF}=$ cerebral blood flow; $\mathrm{CSF}=$ cerebrospinal fluid; $\mathrm{CT}=$ computerized tomography; DRS = disability rating scale; GCS = Glasgow Coma Scale; LDF = laser Doppler flowmetry; MABP = mean arterial blood pressure; $\mathrm{PtiCO}_{2}=$ brain tissue carbon dioxide; $\mathrm{TBI}=$ traumatic brain injury; $\mathrm{TCD}=$ transcranial Doppler. surements of $\mathrm{CBF}$ are difficult. Both $\mathrm{CBF}$ and $\mathrm{CPP}$ are variables that represent the best means of monitoring severely head injured patients. In this study, we aimed to report the outcome of three groups of severely head injured patients based on both CPP and CBF (Group A); ICP alone (Group B) and no monitoring of CPP, CBF, or ICP (Group C). This was done to determine if our CPP and CBF protocols would benefit patients in the long term.

\section{CLINICAL MATERIAL AND METHODS}

\section{Study Protocol}

In Malaysia, all individuals 12 years of age and older receive their national identity cards and are legally considered adults. All examinations were performed continuously except for TCD ultrasonography, which was performed hourly. All signals for the multimodality study (Group A), ICP values (Group B), and arterial blood gas parameters were recorded for 4 days and then were gradually tapered off. During the time between these periods 
(4 years), there was no change in the treatment of head injuries at our hospital and these cases were all managed by the same team from the Department of Anesthesiology and Critical Care Medicine as well as the Neurosciences Unit. This was a prospective randomized study conducted during two time periods. Patients were treated on initial arrival according to a standard protocol for severe TBI. ${ }^{26}$ All patients were treated in the intensive care unit of the Hospital Universiti Sains Malaysia. The study was approved by the local ethics committee.

\section{Description of the Three Study Groups}

Patients in Group A underwent treatment between March 2001 and March 2002 with CBF-based monitoring; those in Groups B and C were treated based on ICP monitoring alone and no monitoring, respectively, between July 1, 1996, and June 30, 1997. All severely head-injured patients who met the following criteria were eligible to participate in the study: 1) age of 12 years or older; 2) consent by next of kin to be involved in the study; 3) GCS ${ }^{4}$ score of 8 or lower; and 4) CT scan of the brain revealing no significant infratentorial pathology. All CT scans of the brain were interpreted according to the Marshall classification. ${ }^{27}$ Exclusion criteria included gunshot wound, coma due to alcohol, drug overdose, or epilepsy, and other major organ injuries. Patients who on arrival had unilateral or bilateral fixed and dilated pupils believed to be due to ongoing herniation, were brain dead, had a known history of hemiparesis, or had any other condition that lowered the patient's functional status score were also excluded. Follow up was conducted at 3, 6, and 12 months. A patient's condition at follow up was graded according to a DRS ${ }^{38}$ and the final score at the end of 1 year was recorded.

\section{Multimodality Monitoring: Group A}

Intracranial pressure was monitored until an acceptable upper limit of $20 \mathrm{~mm} \mathrm{Hg}$ in adults and $14 \mathrm{~mm} \mathrm{Hg}$ in patients between the ages of 12 and 18 years was attained by using a compliance monitor (Spiegelberg $\mathrm{GmbH} \& \mathrm{Co}$., Hamburg, Germany) (CI $>1$ and PVI $>0.5) .{ }^{8}$ A CPP of more than $70 \mathrm{~mm} \mathrm{Hg}$ was maintained using one or more inotropic supports with a central venous pressure between 5 and $10 \mathrm{mg}$. The Saber $2100 \mathrm{CBF}$ sensor (Flowtronics, Phoenix, AZ) works by the thermal diffusion technique, which measures regional cortical blood flow $(\mathrm{ml} / 100$ $\mathrm{g} / \mathrm{min}$ ) in the cortex where the measured area is approximately $1 \mathrm{~cm}$ deep in the cerebral hemisphere and $3 \mathrm{~cm}$ by implication. The sensor measures an area approximately 8 $\mathrm{mm}$ hemispheric due to the size of the gyrus. Its sensor plates are 24-k gold, whereas its wires are solid silver and Teflon-coated. Regional cortical blood flow was maintained by expanding the plasma volume, by using inotropic support, or by implementing other medical methods to maintain a value higher than $50 \mathrm{ml} / 100 \mathrm{~g} / \mathrm{min}$ at all times. ${ }^{16}$ Brain tissue $\mathrm{PO}_{2}$ (Licox, Kiel-Mielkendorf, Germany) was kept at a minimal level of $15 \mathrm{~mm} \mathrm{Hg}$, with a fractional inspired $\mathrm{O}_{2}$ level of 1 for a duration of 24 hours. ${ }^{3,23} \mathrm{StCO}_{2}$ (Invos, Somanetics, USA) was used over each frontal lobe and was maintained at a level higher than $75 \% .{ }^{19}$ A cerebral oximeter (Invos, model 4100; Somanetics Corporation, Troy, MI) was used with a dispos- able regional cerebral $\mathrm{O}_{2}$ saturation sensor on both frontal lobes in adults and was maintained at levels higher than $75 \% .{ }^{19}$ Laser Doppler flowmetry was maintained using a commercially available machine (model DRT4; Moors Instrument, Devon, UK). The LDF measurements were maintained at values of greater than $5 \mathrm{AU}$ with pulsatility. ${ }^{16,20,21,25,32}$ Regional cortical blood flow, brain tissue $\mathrm{PO}_{2}$, and LDF were measured in the most damaged brain according to CT scanning results. Microdialysis was performed at the cortical-subcortical junction in the most damaged brain tissue by using a microdialysis analyzer (CMA 600; Solna, Sweden). 5,29 Jugular venous saturation was maintained from a baseline of 65 to $75 \%$ by using an optical catheter in the dominant jugular bulb (Oximetrix3 system; Abbott Laboratories, Chicago, IL). ${ }^{10,14,30,41}$ All patients with impaired cerebral vasomotor reactivity underwent a cerebral vasomotor reactivity test during which the flow velocity in the middle cerebral artery was monitored intermittently by using a $2-\mathrm{MHz}$ pulsed TCD ultrasonography probe (model MultiDop 2; DWL Electronishe System GmbH, Sipplingen, Germany) inserted at depths of between 4 and $6 \mathrm{~cm} \cdot{ }^{15,28,33,34,42,44,45}$ All patients were positioned with their heads elevated $30^{\circ}$.

\section{Monitoring of ICP Alone: Group B}

Monitoring of ICP alone was performed in patients in Group B by using a ventricular catheter in the right frontal horn, which was attached to an external transducer for a duration of 4 days. Cerebrospinal fluid was drained if ICP was $\geq 20 \mathrm{~mm} \mathrm{Hg}$. In this group, only ICP was monitored plus the basic intensive care parameters of invasive blood pressure, CPP, pulse oximetry, and respiratory rate. Tracking proceeded for at least 4 days if uneventful. Each patient's condition at a 6-month posttreatment follow up was noted.

\section{Conservative Management: Group C}

Group $C$ included those patients whose family refused ICP monitoring but agreed to conservative treatment. These patients underwent hyperventilation to the standard $\mathrm{PaCO}_{2}$ range of 30 to $35 \mathrm{~mm} \mathrm{Hg}^{11}$ via an endotracheal tube for a period of 24 to 48 hours. Repeated CT scans were obtained to decide whether a patient should be weaned from ventilation.

\section{Statistical Analysis}

Data analysis was completed using commercially available software (SPSS, version 10; SPSS, Inc., Chicago, IL). Chi-square and Fisher exact tests were also applied for statistical analysis. Significance was set at a probability level of 0.05 .

\section{RESULTS}

\section{Multimodality Measures: Group A}

Seventeen patients underwent multimodality monitoring, the majority $(58.8 \%)$ of whom were between the ages of 15 and 20 years. Fourteen (82.4\%) were male. A total of $52.9 \%$ of these patients reached the hospital between 4 and 8 hours postinjury. Computerized tomography studies obtained 6 weeks posttreatment revealed normal findings 
in eight patients (47.1\%). A total of 12 patients $(70.6 \%)$ had abnormal pupil reactions, whereas the rest had normal pupillary reactions. Diffuse axonal injuries with Marshall grades of 4 and $3(17.6 \%)$ were associated with extracerebral mass lesions, all of which were subdural hemato- mas. They received craniotomies and ICP monitoring was done in $14(82.4 \%)$. Autoregulation was absent in eight patients $(47.1 \%)$. Jugular venous $\mathrm{O}_{2}$ saturation was abnormal in nine $(52.9 \%)$. Cutaneous infrared spectroscopic measurement of regional $\mathrm{CBF}\left(\mathrm{STcO}_{2}\right)$ was abnormal in 12 patients $(70.6 \%)$. Brain tissue $\mathrm{PO}_{2}$ was abnormal in 15 patients $(88.2 \%)$. Values for ICP, brain tissue $\mathrm{PCO}_{2}, \mathrm{CBF}$, TCD ultrasonography, and microdialysis were abnormal in 13 patients (76.5\%). Results of electroencephalography and evoked potential studies were abnormal in 12 patients (70.6\%). Laser Doppler flowmetry was abnormal in 10 patients $(58.8 \%)$. Brain temperature was higher than $36.6^{\circ} \mathrm{C}$ in 14 patients $(83.4 \%)$. Brain $\mathrm{pH}$ was less than 7.45 in 10 patients $(58.8 \%)$. All patients were treated aggressively to increase their $\mathrm{CPP}, \mathrm{CBF}$, and Brain tissue $\mathrm{PO}_{2}$ as well as to decrease their ICP. None of these patients died. Eight patients $(47.1 \%)$ had a DRS score between 7 and 29 points, whereas nine $(52.9 \%)$ had a DRS score less than 7 points.

The characteristics of patients and their injuries were compared between those who underwent the single modality and those who underwent multimodality treatment. These characteristics included age, sex, time between injury and admission, GCS score, pupillary reaction to light, craniectomy/craniotomy, and CT scanning results. Among these, time between injury and admission $(\mathrm{p}=0.001)$ was statistically significant (Table 1). The relationship between modality type and patient outcome based on Glasgow Outcome Scale scores was also studied. There was a statistically significant difference in outcome among

TABLE 1

Frequency distribution of patient characteristics and injuries

\begin{tabular}{|c|c|c|c|c|c|}
\hline \multirow[b]{2}{*}{ Variable } & \multicolumn{3}{|c|}{ Patient Group (no. of patients [\%]) } & \multirow{2}{*}{$\begin{array}{l}\text { Chi- } \\
\text { Square }\end{array}$} & \multirow{2}{*}{$\begin{array}{c}\mathrm{p} \\
\text { Value* }\end{array}$} \\
\hline & A & B & $\mathrm{C}$ & & \\
\hline \multicolumn{6}{|l|}{ age (yrs) } \\
\hline $12-20$ & $10(37.1)$ & $9(33.3)$ & 8 (29.6) & 7.04 & 0.134 \\
\hline $21-30$ & $5(15.2)$ & $13(39.4)$ & $15(45.5)$ & & \\
\hline$>30$ & $2(9.1)$ & $9(40.9)$ & $11(50.0)$ & & \\
\hline \multicolumn{6}{|l|}{$\operatorname{sex}$} \\
\hline M & $14(20.3)$ & $27(39.1)$ & $28(40.6)$ & 0.33 & 0.850 \\
\hline $\mathrm{F}$ & $3(23.0)$ & $4(30.8)$ & $6(46.2)$ & & \\
\hline \multicolumn{6}{|c|}{$\begin{array}{l}\text { time between injury } \\
\text { and admission }\end{array}$} \\
\hline$\leq 4$ hours & $15(24.2)$ & $30(48.4)$ & $17(27.4)$ & 21.09 & $<0.001$ \\
\hline$>4$ hours & $2(10.0)$ & $1(5.0)$ & $17(85.0)$ & & \\
\hline \multicolumn{6}{|l|}{ GCS score } \\
\hline 3 to 5 & $9(17.0)$ & $17(32.1)$ & 27 (50.9) & 5.57 & 0.062 \\
\hline 6 to 8 & $8(27.6)$ & $14(48.3)$ & $7(24.1)$ & & \\
\hline \multicolumn{6}{|c|}{$\begin{array}{l}\text { pupillary reaction } \\
\text { to light }\end{array}$} \\
\hline normal & $5(12.8)$ & 14 (35.9) & $20(51.3)$ & 4.05 & 0.132 \\
\hline abnormal & $12(27.9)$ & $17(39.5)$ & 14 (32.6) & & \\
\hline \multicolumn{6}{|l|}{ CT scan results } \\
\hline normal & $8(22.9)$ & $13(37.1)$ & $14(40.0)$ & 0.17 & 0.918 \\
\hline abnormal & $9(19.1)$ & $18(38.3)$ & $20(42.6)$ & & \\
\hline
\end{tabular}

* The level of significance was set at a probability value of 0.05 . patients in the three different treatment groups $(\mathrm{p}=0.003$; Table 2).

\section{Groups Subject to Single-Modality Monitoring (Group B) and no Monitoring (Group C)}

Sixty-five patients were in both Groups B and C, of whom the majority were male (55 male patients [84.6\%] and 10 female [15.4\%]; Table 1). The majority of these victims were within the age group of 13 to 39 years with a mean age of 27.4 years.

Most (72.3\%) of these cases were seen within 8 hours postinjury, and $76.9 \%$ had been referred from within a 50$\mathrm{km}$ radius.

A total of $69.2 \%$ of patients were motorcyclists and drivers, with motorcyclists being the dominant group. Fortyfour $(67.7 \%)$ of these patients had an initial GCS score of less than 8 at the time of their accident. Patients who had a GCS score of more than 9 were referred to HUSM when their scores had decreased to less than 8 within a period of 8 hours of trauma. A total of $44.6 \%$ of the patients who were referred to our Emergency Department were intubated on arrival.

Most of the referred cases were those in which CT scanning had demonstrated signs of diffuse axonal injury (41.5\% had a diffuse head injury with a Marshall Grade 4, 26.2\% had diffuse head injury with Marshall Grade 3, and $32.3 \%$ had extracerebral mass lesions). These patients required cerebral protection and hyperventilation.

A total of $32.3 \%$ of patients had extradural (10 patients) and subdural hematomas (11 patients) and underwent emergency evacuation of the clots. Statistically, there was no significant difference in the number of patients who underwent ICP monitoring compared with those who did not. As mentioned earlier, Group B included patients who had undergone ICP monitoring and those in Group $\mathrm{C}$ were treated without ICP monitoring. All patients in Group B were on solely intraventricular pressure monitoring, allowing for CSF drainage.

The mean duration of hyperventilation was 43.5 hours. During that period, the condition of 10 patients (15.4\%) had deteriorated and their pupils had become fixed and dilated. Fourteen patients (21.5\%) had a period of hypotension, and $23(35.4 \%)$ required tracheostomy due to poor recovery.

In terms of outcome at 1 year, of 65 patients, 42 (64.6\%) had a favorable outcome according to the DRS and 17 (26.2\%) died. Only six patients (9.2\%) had a poor outcome.

TABLE 2

Relationship between type of monitoring modality and patient outcome

\begin{tabular}{lrllll}
\hline \hline \multirow{2}{*}{$\begin{array}{c}\text { Monitoring } \\
\text { Modality }\end{array}$} & \multicolumn{2}{c}{ Outcome $($ no. of patients [\%])* } & & \\
\cline { 2 - 4 } & Good & Poor & Death & Chi-Square & p Value $\dagger$ \\
\hline multimodality & $9(52.9)$ & $8(47.1)$ & $0(0.0)$ & 16.40 & 0.003 \\
ICP only & $21(67.7)$ & $2(6.5)$ & $8(25.8)$ & & \\
none & $21(61.8)$ & $4(11.8)$ & $9(26.4)$ & & \\
\hline
\end{tabular}

* The DRS scores were as follows: good outcome, less than 7 points; poor outcome, 7 to 29 points; death, 30 points.

$\dagger$ The level of significance was set at a probability value of 0.05 . 
Twenty patients were older than 30 years of age and the rest were between 10 and 21 years. We found that there was a dramatic increase in the mortality rate in patients older than 30 years. Mortality rates were $14 \%$ in the 10 - to 30 -year-old age group and 55\% in those older than 30 years.

With respect to the distribution of age and catheter insertion, the mean age for those in Group B was 26 years and the mean age for those in Group $\mathrm{C}$ was 28.7 years. In Group B, the youngest patient was 3.2 years and the oldest was 66.1 years. In Group C, the youngest patient was 4 years and the oldest patient was 71.2 years. There was no significant difference in the age distribution in both groups.

Of the group of 31 patients who had undergone monitoring (Group B), 27 were male and four were female. In the group of 34 patients who did not receive monitoring (Group C), 28 were male and six were female. There was no significant difference in sex distribution in both groups $(\mathrm{p}=0.42$, Fisher exact test $)$.

A total of 47 patients (72\%) arrived within 4 hours postinjury, whereas 18 patients $(28 \%)$ arrived between 4 and 12 hours. The mean time delay between injury and evaluation/treatment for patients with and those without ICP monitoring was 7 hours 30 minutes and 5 hours 40 minutes, respectively. This difference was not significant $(\mathrm{p}=0.24)$.

We found a significant difference between Groups B and $\mathrm{C}$ with respect to GCS scores $(\mathrm{p}=0.03)$. A greater number of patients with a GCS score of less than 8 did not undergo ICP monitoring (27 of 44 patients), whereas those with a GCS score of more than 9 deteriorated within 8 hours even with ICP monitoring (14 of 21 patients). This was due to the fact that these patients' families refused ICP monitoring and thus were put in the conservative treatment group.

There was no significant difference between the number of patients with a normal and an abnormal pupillary response to light; that is, patients were distributed equally between Groups B and C. Of the total number of patients, 31 demonstrated significant pupillary changes-fixed and dilated-indicating deterioration. Eight of these patients had not undergone ICP monitoring, but two had.

Various types of head injuries encountered and the number of cases in Groups B and C were classified according to the Marshall system on CT studies. Most patients had diffuse axonal head injury and mass lesion with cerebral edema. Both Groups B and C had an equal distribution of cases. There was not statistically significant difference $(p=0.61)$ between these two groups.

Also, there was no statistically significant difference in the number of cases treated with surgery for the evacuation of clots in Groups B and C. The mean duration of ventilation for patients in Groups B and C was 43.7 and 42.3 hours, respectively $(\mathrm{p}>0.05)$. Of these 65 patients, 23 patients required a tracheostomy for protection of the airway during the first 2 weeks of post-intensive care for bronchial toileting. Equal numbers of patients were distributed in both groups.

During the course of cerebral protection, 14 patients experienced a period of hypotension, which required inotropic support. Equal numbers of cases were represented in the two groups. Among patients in Group B, the highest ICP recorded during the period of cerebral protection was $34 \mathrm{~mm} \mathrm{Hg}$, the lowest was $4 \mathrm{~mm} \mathrm{Hg}$, and the mean was $15.7 \mathrm{~mm} \mathrm{Hg}$.

All patients in Group B had their ICP monitored for 4 days. There was a strong relationship between patient outcome and the course of ICP during the period of cerebral protection. Patients with an ICP less than $10 \mathrm{~mm} \mathrm{Hg} \mathrm{had}$ a good recovery or were moderately disabled, whereas there was a mortality rate of 55\% among those with an ICP greater than $20 \mathrm{~mm} \mathrm{Hg}$. Of the nine patients who had ICP levels greater than $20 \mathrm{~mm} \mathrm{Hg}$, only four responded to intervention therapy that used CSF drainage.

\section{DISCUSSION}

Targets for basic intensive care practice in the area of CPP and CBF have been widely debated and the subject of recent discussion. In our group of patients we found a significantly better outcome with the use of multimodality monitoring compared with the use of ICP monitoring alone or conservative management. This was reflected by no deaths in the multimodality group compared with the other two groups, which had an approximately $25 \%$ fatality rate $(\mathrm{p}=0.003)$. Other studies on CBF have demonstrated that an inadequate level of $\mathrm{CBF}$ is an important cause of secondary ischemic damage. .7, $73,44^{-}$Correlation studies indicate that cerebral oximetry-whether measured invasively or noninvasively - can be related to CPP, thus improving brain tissue $\mathrm{PO}_{2}$, lactate, and glucose levels. Cerebral blood flow, CPP, and ICP will supplement brain tissue $\mathrm{PO}_{2}$ as demonstrated in our patients. This may help us in the treatment of hypertension in patients with head injuries or those with hyperemia, thus assisting with the lowering of $\mathrm{CPP}$ without disastrous changes in $\mathrm{CBF}$ and intracellular oxygen, lactate, and $\mathrm{O}_{2}$ values. ${ }^{35}$ Multimodality monitoring has been proven to be helpful in the long term. . $^{31,36,43,44}$

The severity and type of impact incurred during head injury will substantially influence the structural lesions that ensue. The acceleration/deceleration forces produced by falls and motor vehicle accidents can produce axonal dysfunction and injury, brain contusions, and axial extraaxial hematomas. ${ }^{39}$ Such a macroscopic injury is associated with microscopic and ultramicroscopic changes, including ischemia, astrocyte swelling with microvascular compromise, BBB disruption, and inflammatory cell recruitment.

Intracranial hematomas may not only raise ICP and worsen cerebral hypoxia, but also be responsible for EAA release, inflammation, and microvascular dysfunction. The microvascular dysfunction may in turn limit the ability of the injured brain to cope with minor variations in physiology, with elevation of the lower limit of autoregulation to a CPP level of 60 to $70 \mathrm{~mm} \mathrm{Hg}$ (compared with that in normal individuals who tend to maintain $\mathrm{CBF}$ at $\mathrm{CPP}$ values of $50 \mathrm{~mm} \mathrm{Hg}$ ). At later stages, the presence of extravascular blood may predispose to large vessel spasm, with the potential for distal hypoperfusion and ischemia. ${ }^{28,36}$

Historically, CBF is thought to show a triphasic behavior. Soon after head injury ( $>12$ hours), global CBF is reduced, sometimes to ishemic levels. Between 12 and 24 
hours postinjury, $\mathrm{CBF}$ increases and the brain may exhibit supranormal CBF. Although many investigators refer to this phenomenon as hyperemia, the absence of consistent reductions in cerebral oxygen extraction indicates the retention of flow-metabolism coupling and a more appropriate label of hyperperfusion. Cerebral blood flow values begin to decrease again several days following head injury, and in some patients these reductions in CBF may be associated with marked increases in large vessel flow velocity, which can be revealed on TCD ultrasonography and suggest vasospasm.

Increases in CBF and cerebral blood volume from the 2nd day postinjury onward make vascular engorgement an important contributor to intracranial hypertension. The BBB appears to become leaky between the 2nd and 5th days posttrauma, and vasogenic edema then contributes to brain swelling.

Basic physiology supports the benefit of maintaining $\mathrm{CBF}$ and oxygenation, and these assumptions are confirmed by data from the Traumatic Coma Data Bank ${ }^{12,13}$ and other sources demonstrating the detrimental effects of hypotension (systolic blood pressure $<90 \mathrm{~mm} \mathrm{Hg}$ ) and hypoxia $\left(\mathrm{PaO}_{2}\right.$ levels $\left.<60 \mathrm{~mm} \mathrm{Hg}[8 \mathrm{kPa}]\right)$ in the early and later phases of head injury on patient outcome. Data from several studies focused on break points for cerebral autoregulation in patients with head injury have demonstrated preserved cerebrovascular autoregulation with the maintenance of CBF at CPP levels greater than 60 to $70 \mathrm{~mm} \mathrm{Hg} .{ }^{9,10,40}$ Furthermore, ischemia is a consistent finding in fatal head injury, ${ }^{9}$ and retrospective studies from several groups have revealed that outcome is improved in patients with fewer episodes of CPP or MABP reduction, ${ }^{38}$ aggressive CPP management, ${ }^{44}$ or retained autoregulation. ${ }^{15}$

The need to maintain cerebral oxygenation and CPP predicates the use of the monitoring required to achieve the therapeutic targets. Commonly used bedside monitoring techniques include TCD ultrasonography for noninvasive estimation of $\mathrm{CBF}$, jugular venous saturation monitoring, and monitoring of electrical activity in the brain. With these techniques, investigators seek to estimate CBF in the presence of an adequate CPP, to estimate the adequacy of oxygen delivery to the brain, and to document the consequences of a possible oxygen deficit or a particular drug therapy on brain function.

Reductions in the flow velocity of the middle cerebral artery provide a useful marker of reduced CPP in the setting of intracranial hypertension, although episodic rises in ICP may also be caused by hyperemia, which may be diagnosed by increases in flow velocity demonstrated on TCD ultrasonography.

Despite the neuropathological evidence of ischemia in patients with fatal head injury, antemortem evidence of ischemia from reductions in CBF were generally modest in the first few days following injury. Furthermore, most patients exhibited arteriojugular venous difference of $\mathrm{O}_{2}$ within the normal range, implying that the $\mathrm{CBF}$ reductions were appropriately coupled to decreases in cerebral metabolic rates for oxygen. ${ }^{37}$ Two different approaches have provided explanations for these observations. Ultra-early $(<12$ hours) $\mathrm{CBF}$ measurements following head injury have provided clear evidence that more than $30 \%$ of pa- tients exhibit global $\mathrm{CBF}$ reductions lower than commonly accepted ischemic thresholds $(<18 \mathrm{ml} / 100 \mathrm{~g} / \mathrm{min})$. Later measurements showed elevation of CBF to nonischemic levels by 24 to 48 hours postinjury. ${ }^{28}$ These findings have been generally confirmed by other study data; however, even at early time points, arteriojugular venous difference of $\mathrm{O}_{2}$ remained relatively low despite a markedly low $\mathrm{CBF}$, with few patients demonstrating increases above $9 \mathrm{ml} / 100 \mathrm{~g} / \mathrm{min} \cdot{ }^{28,37}$

One explanation for the conflict between these clinical findings and the neuropathological evidence of ischemia may be found in the physiological heterogeneity of the injured brain. ${ }^{22}$ Both conventional monitoring methods and newer techniques are limited by the fact that they detect either globally averaged or highly localized abnormalities in cerebral physiology and may be unable to detect regional abnormalities in the metabolically heterogeneous injured brain.

Although individual monitoring techniques provide in formation regarding specific aspects of cerebral function, the correlation of data from several modalities has several advantages in the management of head injury. Integration of monitored variables allows cross-validation and artifact rejection, better understanding of pathophysiology, and the potential to target therapy.

Most center personnel agree on the need to maintain CPP higher than 60 to $70 \mathrm{~mm} \mathrm{Hg}$ by either decreasing ICP or increasing MABP. Although MABP is usually maintained with volume expansion, inotropes, and vasopressors, the relative efficiency of each of these interventions in maintaining CPP has not been investigated. Indeed, we have no data on the safety of high doses of vasoactive agents in the presence of BBB disruption. Drainage of CSF (when possible), mannitol administration, induction of hyperventilation, and the use of central nervous system depressants (typically barbiturate agents) have all been used to reduce ICP. The debate in this area has focused on the means of optimizing CPP at a level higher than $70 \mathrm{~mm}$ $\mathrm{Hg}$ and maintaining CBF greater than $50 \mathrm{ml} / 100$ $\mathrm{g} / \mathrm{min} .{ }^{9,10,14,15,40,44}$ Rosner, et al., ${ }^{40}$ have been the most enthusiastic proponents of the use of hypervolemia and hypertension to increase MABP and induce secondary reductions in ICP. Cruz ${ }^{14}$ on the other hand, has proposed the use of "optimized hyperventilation" (guided by jugular venous oxygen saturation monitoring) to reduce ICP and hence increase CPP. It is likely that several different pathophysiological mechanisms coexist in individual patients, and both approaches are likely to have a role if applied appropriately. It must be remembered that both hyperventilation and induced hypertension have clearly recognized systemic and cerebral side effects, and the extent of their use will be limited by a risk/benefit ratio. ${ }^{11}$

In both Groups $\mathrm{A}$ and $\mathrm{B}$, the time between injury and admission was much better in the CPP management group when compared with the ICP management group. Note that the establishment of the Masters of Medicine (Emergency Medicine) course in June 1998 and the national upgrading of the emergency services occurred during the 4 years between these studies. These improvements would have enhanced the pre-hospital management of patients with head injuries, and thus prevent hypotension and hypoxia. 
In Table 2, the relationship between modality type and patient outcome is shown. Even though there were no deaths in the patients in the multimodality group, eight patients $(47 \%)$ had poor outcomes with a DRS score between 7 and 29. Of these eight patients, seven had DRS scores between 7 and 11 (moderate disability) and one had a score of 12 (severe disability). None of them was in a vegetative state.

In practice, our established head injury protocols represent a hybrid approach. Initial baseline monitoring and therapy are applied to all patients, and refractory problems are dealt with by escalating therapy, with the choice of intervention being determined by clinical presentation and physiological monitoring. Rarely, interventions or present significant risks (for example, barbiturate coma) are used as a last resort. In our group of patients, no one required induction of thiopentone coma.

Age and time of admission together with the mode of monitoring has been found to be significant in improving patient outcome after a 12-month follow-up period. Death has been the focus of outcome in this study in which multimodality monitoring has been associated with superior results compared with the others. Aggressive CBF, CPP, brain tissue $\mathrm{PO}_{2}, \mathrm{CO}_{2}, \mathrm{pH}$ with laser flowmetry guided with TCD velocity values, and intracellular microdialysis monitoring and active management will improve patient outcome. A prospective study is currently underway to subanalyze the multimodalities and their importance as well as their cost effectiveness in treating children with head injuries.

\section{Acknowledgments}

We acknowledge Drs. Zamzuri Idris and Ruwaida Isa who participated in this study as part of their fulfillment for the Masters of Surgery (Neurosurgery) USM and Masters of Medicine (Anesthesiology) USM, respectively.

\section{References}

1. Ackermann RF, Lear JL: Glycolysis-induced discordance between glucose metabolic rates measured with radiolabeled fluorodeoxyglucose and glucose. J Cereb Blood Flow Metab 9:774-785, 1989

2. Adams JH, Graham DI, Gennarelli TA: Head injury in man and experimental animals: neuropathology. Acta Neurochir Suppl 32:15-30, 1983

3. al-Rawi PG, Hutchinson PJA, Gupta AK, et al: Multiparameter brain tissue monitoring-correlation between parameters and identification of CPP thresholds. Zentralbl Neurochir 61: 74-79, 2000

4. Anonymous: The Brain Trauma Foundation. The American Association of Neurological Surgeons. The Joint Section on Neurotrauma and Critical Care. Glasgow coma scales score. J Neurotrauma 17:563-571, 2000

5. Benveniste H, Huttemeier PC: Microdialysis - theory and application. Prog Neurobiol 35:195-215, 1990

6. Bouma GJ, Muizelaar JP, Stringer WA, et al: Ultra-early evaluation of regional cerebral blood flow in severely head-injured patients using xenon-enhanced computerized tomography. J Neurosurg 77:360-368, 1992

7. Bruce DA, Langfitt TW, Miller JD, et al: Regional cerebral blood flow, intracranial pressure, and brain metabolism in comatose patients. J Neurosurg 38:131-144, 1973

8. Chambers IR, Siddique MS, Banister K, et al: Clinical comparison of the Spiegelberg parenchymal transducer and ventricular fluid pressure. J Neurol Neurosurg Psychiatry 71:383-385, 2001

9. Chan KH, Dearden NM, Miller JD, et al: Multimodality monitoring as a guide to treatment of intracranial hypertension after severe brain injury. Neurosurgery 32:547-553, 1993

10. Chan KH, Miller JD, Dearden NM, et al: The effect of changes in cerebral perfusion upon middle cerebral artery blood flow velocity and jugular bulb venous oxygen saturation after severe brain injury. J Neurosurg 77:55-61, 1992

11. Chesnut RM: Hyperventilation versus cerebral perfusion pressure management: time to change the question. Crit Care Med 26:210-212, 1998

12. Chesnut RM, Marshall LF, Klauber MR, et al: The role of secondary brain injury in determining outcome from severe head injury. J Trauma 34:216-222, 1993

13. Chesnut RM, Marshall SB, Piek J, et al: Early and late systemic hypotension as frequent and fundamental source of cerebral ischaemia following severe brain injury in the Traumatic Coma Data Bank. Acta Neurochir Suppl 59:121-125, 1993

14. Cruz J: The first decade of continuous monitoring of jugular bulb oxyhemoglobin saturation: management strategies and clinical outcome. Crit Care Med 26:344-351, 1998

15. Czosnyka M, Smielewski P, Kirkpatrick P, et al: Continuous assessment of the cerebral vasomotor reactivity in head injury. Neurosurgery 41:11-19, 1997

16. Dickman CA, Carter LP, Baldwin HZ, et al: Continuous regional cerebral blood flow monitoring in acute craniocerebral trauma. Neurosurgery 28:467-472, 1991

17. Dienel GA: Energy generation in the central nervous system, in Edvinsson L, Krause DN (eds): Cerebral Blood Flow and Metabolism, ed 2. New York: Lippincott Williams \& Wilkins, 2002, pp 140-161

18. Duckrow RB, LaManna JC, Rosenthal M, et al: Oxidative metabolic activity of cerebral cortex after fluid-percussion injury in the cat. J Neurosurg 54:607-614, 1981

19. Dunham CM, Sosnowski C, Porter JM, et al: Correlation of noninvasive cerebral oximetry with cerebral perfusion in the severe head injured patient: a pilot study. J Trauma 52:40-46, 2002

20. Eggert HR, Blazek V: Optical properties of human brain tissue, meninges, and brain tumors in the spectral range of 200 to 900 nm. Neurosurgery 21:459-464, 1987

21. Frerichs KU, Feuerstein GZ: Laser-Doppler flowmetry. A review of its application for measuring cerebral and spinal cord blood flow. Mol Chem Neuropathol 12:55-70, 1990

22. Graham DI, Ford I, Adams JH, et al: Ischaemic brain damage is still common in fatal non-missile head injury. J Neurol Neurosurg Psychiatry 52:346-350, 1989

23. Hoffman WE, Charbel FT, Edelman G: Brain tissue oxygen, carbon dioxide, and $\mathrm{pH}$ in neurosurgical patients at risk for ischaemia. Anesth Analg 82:582-586, 1996

24. Inglis FM, Bullock R, Chen MH, et al: Ischaemic brain damage associated with tissue hypermetabolism in acute subdural haematoma: reduction by a glutamate antagonist. Acta Neurochir 51:277-279, 1990

25. Lam JM, Hsiang JN, Poon WS: Monitoring of autoregulation using laser Doppler flowmetry in patients with head injury. J Neurosurg 86:438-445, 1997

26. Maas AIR, Dearden M, Teasdale GM, et al: EBIC-guidelines for management of severe head injury in adults. European Brain Injury Consortium. Acta Neurochir 139:286-294, 1997

27. Marshall LF, Marshall SB, Klauber MR, et al: A new classification of head injury based on computerized tomography. J Neurosurg 75 (Suppl):S14-S20, 1991

28. Martin NA, Patwardhan RV, Alexander MJ, et al: Characterization of cerebral hemodynamic phases following severe head trauma: hypoperfusion, hyperemia, and vasospasm. J Neurosurg 87:9-19, 1997

29. McIntosh TK, Smith DH, Meaney DF, et al: Neuropathological 
sequelae of traumatic brain injury: relationship to neurochemical and biomechanical mechanisms. Lab Invest 74:315-342, 1996

30. McLeod AD, Igielman F, Elwell C, et al: Measuring cerebral oxygenation during normobaric hyperoxia: a comparison of tissue microprobes, near-infrared spectroscopy, and jugular venous oximetry in head injury. Anesth Analg 97:851-856, 2003

31. Meixensberger J, Jaeger M, Vath A, et al: Brain tissue oxygen guided treatment supplementing ICP/CPP therapy after traumatic brain injury. J Neurol Neurosurg Psychiatry 74: 760-764, 2003

32. Meyerson BA, Gunasekera L, Linderoth B, et al: Bedside monitoring of regional cortical blood flow in comatose patients using laser Doppler flowmetry. Neurosurgery 29:750-755, 1991

33. Muizelaar JP, Lutz HA III, Becker DP: Effect of mannitol on ICP and CBF and correlation with pressure autoregulation in severely head-injured patients. J Neurosurg 61:700-06, 1984

34. Newell DW, Aaslid R, Lam A, et al: Comparison of flow and velocity during dynamic autoregulation testing in humans. Stroke 25:793-797, 1994

35. Nordstrom $\mathrm{CH}$, Reinstrup $\mathrm{P}, \mathrm{Xu} \mathrm{W}$, et al: Assessment of the lower limit for cerebral perfusion pressure in severe head injuries by bedside monitoring of regional energy metabolism. Anesthesiology 98:809-814, 2003

36. Obrist WD, Langfitt TW, Jaggi JL, et al: Cerebral blood flow and metabolism in comatose patients with acute head injury. Relationship to intracranial hypertension. J Neurosurg 61: 241-253, 1984

37. Paulson OB, Strandgaard S, Edvinsson L: Cerebral autoregulation. Cerebrovasc Brain Metab Rev 2:161-192, 1990

38. Rappaport M, Hall KM, Hopkins K, et al: Disability rating scales for severe head injury: coma to community. Arch Phys Med Rehabil 63:118-123, 1982

39. Reilly PL, Graham DI, Adams JH, et al: Patients with head injury who talk and die. Lancet 2:375-377, 1975

40. Rosner MJ, Rosner SD, Johnson AH: Cerebral perfusion pressure: management protocol and clinical results. J Neurosurg 83:949-962, 1995

41. Sheinberg M, Kanter MJ, Robertson CS, et al: Continuous monitoring of jugular venous oxygen saturation in head-injured patients. J Neurosurg 76:212-217, 1992

42. Smielewski P, Czosnyka M, Kirkpatrick P, et al: Evaluation of transient hyperemic response test in head-injured patients. J Neurosurg 86:773-778, 1997

43. Steiner LA, Czosnyka M: Should we measure cerebral blood flow in head-injured patients? Br J Neurosurg 16:429-439, 2002

44. Steiner LA, Czosnyka M, Piechnik SK, et al: Continuous monitoring of cerebrovascular pressure reactivity allows determination of optimal cerebral perfusion pressure in patients with traumatic brain injury. Crit Care Med 30:733-738, 2002

45. Wagner BP, Gertsch S, Ammann RA, et al: Reproducibility of the blood flow index as noninvasive bedside estimation of cerebral blood flow. Intensive Care Med 29:196-200, 2003

Manuscript received October 9, 2003.

Accepted in final form November 19, 2003.

Address reprint requests to: Jafri Malin Abdullah, M.D., Ph.D., Neurosciences Unit, School of Medical Sciences, Universiti Sains Malaysia, 16150 Kubang Kerian, Kelantan, Malaysia. email: unitneurosainsppspusm@yahoo.com. 